Technical Assistance Project: PCB Regulations and Their Application to Deactivation and Decommissioning Activities

Office of Environmental Policy and Assistance, RCRA/CERCLA Division (EH-413)

April 1996

\section{The Issue}

DOE's economic development plans involve efforts to deactivate and decommission (D\&D) or refurbish site buildings and operational facilities for other uses. As a result of these efforts, site personnel must decide on the disposition of stored materials (i.e., whether they should be saved, recycled, or discarded). In particular, these stored materials include increasing numbers of excess and/ or unwanted oil-filled equipment (e.g., transformers, hydraulic systems, and heat transfer systems) and oil-containing 'orphaned' drums. Because oil, oil-filled equipment, and oil-containing drums can also contain polychlorinated biphenyls (PCBs), it is essential that site personnel become aware of the regulations applicable to PCBs. Adherence to these regulations will minimize DOE hazardous material management liabilities. A recent incident at a DOE facility provides a case in point with important lessons to be learned for all sites within the DOE complex.

\section{The Incident}

In September 1994, a DOE contractor was notified by a used oil recycling company that a used oil shipment contaminated with PCBs, at a concentration of 480 parts per million (ppm), had apparently originated from that facility. The DOE contractor traced the PCB contamination back to four drums of a 22drum shipment, which had been manifested as nonhazardous used oil. Due to a number of oversights that occurred during both the shipment and recycling activities, some of this oil was processed and distributed in commerce to the public as recycled motor and transmission oil. The distributed oil has been recalled by the U.S. Environmental Protection
Agency jointly with DOE. The following summary of events is based on an internal investigation performed by DOE facility personnel.

From the mid-1960s until 1980, a DOE contractor operated an experimental facility that required the use of both $P C B$ and non-PCB electrical equipment (e.g., transformers). When the operations ended, the dielectric oil from the transformers was drained into a number of 55-gallon drums. About 20 drums of dielectric oil were placed into storage for future use, and about 20 drums of PCBs were stored pending disposal. The two types of material were stored in the same small oil storage building. About one year later, a number of the drums of the non-PCB oil were removed from storage for a new electrical use, and the PCB-containing drums were disposed according to regulation.

However, it appears from a reconstruction of the events that four drums may have been inadvertently interchanged so that four drums of PCB oil may have remained in storage. This mistake could have been made because the drums were not uniformly labelled, segregated, or properly marked as PCBs as required by regulation (40 CFR 761.40).

In 1987, a labelling effort was conducted in the storage building. Because of the earlier unknown shipping error, all the drums in that storage area were labelled as Diala-AX (nonPCB) including the 4 drums containing PCB oil. It should be noted that the investigators also brought to light other inappropriate practices and procedures that occurred during the 1987 drum labelling effort.

Q Printed on Recycled Paper 
In 1994, an equipment upgrade eliminated the need to retain the remaining Diala-AX and the drums were scheduled for disposal. The onsite waste generator determined inappropriately that the drum labelling served as sufficient process knowledge and that the oil was Diala-AX which, the Material Safety Data Sheet states, contains no detectable levels of PCB. The waste management organization arranged to have the oil shipped.

Because this was an unusually large used oil shipment (22 drums) and the drum contents were believed to be homogeneous, the transporter instructed the DOE contractor waste management personnel to take a composite sample for testing from only four of the drums for comparison against the waste acceptance criteria (1 ppm PCB). The DOE contractor received verbal test results from the transporter, which indicated that no PCBs were detected. However, no written test results were received at this time. Based on the verbal results, the used oil was transported to the recycler for processing.

Upon receipt of the used oil, the recycler took samples and sent them for analysis. However, the recycling company processed the used oil before analytical results were available. As a result of this combination of assumptions and oversights, the original four drums of PCB oil, mislabelled as Diala-AX, were mixed with other used oils in a 21,500 gallon tank and processed. The resulting product was distributed in commerce prior to receipt of the final laboratory testing report. The recycler was notified by one of its customers that it had detected PCB contamination in the product from the recycler. Subsequent testing traced the PCB contamination back to the 22-drum shipment from the DOE facility. The contamination was reported to the DOE contractor and EPA.

The DOE contractor sampled the residual material in all 22 drums. Data results from analysis of the samples indicated that four of the drums had PCB levels of at least $70 \%$, and the remaining drums had PCB levels ranging from 1.8 to $350 \mathrm{ppm}$, likely due to cross contamination during pump-out for shipment.
To date, this incident has resulted in internal investigation consisting of DOE and DOE contractor management, administrative, legal, environmental compliance, and waste management personnel. A settlement agreement has been entered into between the DOE contractor and the recycler under which the DOE contractor agreed to pay for the removal and disposal of the PCB-contaminated oil. In addition, there is the possibility of regulatory enforcement action.

\section{Causal Factors Analysis}

It appears that the causal factors in this incident lie both with the general waste management practices and the specific compliance with applicable regulatory requirements.

In looking back at the sequence of events, this incident and its potential liability to DOE could likely have been avoided if the DOE contractor had complied with applicable regulatory requirements. After the DOE contractor shut down one of its operations (1980), transformer oils were drained and stored for future reuse or disposed. The regulatory requirements applicable to the $\mathrm{PCB}$ Transformer oil included storing in appropriate containers (40 CFR 761.65(c)), immediately marking the drums with the mark $M_{\mathrm{L}}$ (40 CFR 761.40), and storing the drums in a facility which meets the requirements of 40 CFR 761.65 (b). [Section 761.30(a)(2)(vi) requires that dielectric fluid with a PCB concentration greater than $50 \mathrm{ppm}$ used for servicing transformers be stored as if it were in storage for disposal (i.e., meet all the requirements of 761.65(b)) even though the liquids may be in storage for reuse.] PCB oils at some time were placed in unmarked drums and stored. If the PCB oils had been properly marked and segregated, as required, they would not have been marked "Diala-AX."

Best management practices also play an important role in reducing environmental liability and associated waste management costs. In this case, the improper use of "process knowledge" led to the shipment of wastes without adequate characterization. 


\section{DISCLAIMER}

This report was prepared as an account of work sponsored by an agency of the United States Government. Neither the United States Government nor any agency thereof, nor any of their employees, makes any warranty, express or implied, or assumes any legal liability or responsibility for the accuracy, completeness, or usefulness of any information, apparatus, product, or process disclosed, or represents that its use would not infringe privately owned rights. Reference herein to any specific commercial product, process, or service by trade name, trademark, manufacturer, or otherwise does not necessarily constitute or imply its endorsement, recommendation, or favoring by the United States Government or any agency thereof. The views and opinions of authors expressed herein do not necessarily state or reflect those of the United States Government or any agency thereof. 


\section{DISCLAIMER}

Portions of this document may be illegible in electronic image products. Images are produced from the best available original document. 
Compounding the problem was the DOE contractor's reliance on the vendor's sampling protocols which increased DOE's potential environmental liability. The lessons learned from this situation are:

- Use "process knowledge" appropriately: Process knowledge assumes that you know the exact source and history of the waste, and that there was no time when the waste was not under strict administrative and/or engineering controls. This was not the case for the drums in this situation. The ambiguity of the drum labelling and the lack of administrative or engineering controls from 1980 to 1994 , as described above, should have indicated the need for sampling and analysis of the materials in all of the drums. In this case, even the use of an equal aliquot sample compositing protocol, combining material from all 22 drums would have shown the presence of PCBs above the waste acceptance criteria (1 ppm); and, following site procedures, led to the identification of individual drums of PCB oils regulated for disposal (i.e., $>50 \mathrm{ppm}$ ).

- Bear in mind DOE's potential environmental liability: All activities at DOE facilities intended to control the release of contaminants or shipment of waste and/or unwanted/surplus materials should be designed to eliminate future liability to the greatest possible extent. In this case, the DOE contractor had not developed a sampling and analysis requirement for used oil shipments that would ensure environmental compliance.

As a result, the DOE contractor relied on the vendor's protocol which was not sufficient to adequately characterize the waste shipment.

\section{Additional Considerations for D\&D Activities}

The government has codified its concern for environmental liability in 41 CFR 101 and 109. These sections of the Federal Property Management regulations deal with the disposition of (surplus) hazardous materials or property including donation, sale, or transfer (41 CFR
101), and the requirements for release of radioactively and chemically contaminated DOE property, including precious metals, shielding material, and lead (41 CFR 109). These rules require that all suspect materials and/or equipment be reviewed prior to release (sale, donation, disposal, etc.) to determine if all Federal environmental regulations and standards have been met. Where such standards do not exist, accepted national consensus standards must be met.

In addition, if not already dealt with in existing procurement policy, waste management personnel should work with contract specialists in the procurement office to ensure that the issue of liability caused by negligence, in whole or in part, of the recycler/disposer is addressed in all contracts or contractual-type instruments (e.g., purchase orders). Furthermore, whatever contract vehicle is used should ensure that only responsible recycling / disposal contractors are dealt with and that a recycling/disposal contract need not necessarily be awarded to the lowest bidder.

\section{Technical Assistance Available}

This scenario is only one of many that may be encountered during ongoing deactivation and decommissioning or refurbishing operations. Most environmental restoration teams have project managers and environmental compliance support staff who are well versed in RCRA and CERCLA regulations. However; many of these same DOE and contractor staff are not familiar with the intricacies of the PCB regulations promulgated under TSCA. It is a common misconception that PCBs are only associated with electrical equipment such as transformers and capacitors. Although most of the PCBs are in electrical equipment (e.g., switches/reclosers, light ballasts, small capacitors, and voltage regulators), a number of other common items also contain PCBs. Prior to 1976, PCBs were employed in numerous other uses because of their chemical properties. Heat transfer systems, electromagnets, metal cutting and shaping tools, ventilation gaskets, adhesives, and carbonless copy paper are examples of items that commonly contained PCBs. 
- The Office of Environmental Policy and

Assistance (EH-41) has developed several guidance documents to assist the Department's Program Offices and Field Organizations in identifying PCB management issues and complying with the applicable regulations. These guidance documents include a series of Information Briefs on such topics as marking, storage, disposal, and recordkeeping/reporting (see references below). EH-41 has also developed a comprehensive guidance document entitled Guidance on the Management of Polychlorinated Biphenyls DOE/EH-0350, November 1993. For more information on these guidance documents, you may contact Carolyn Thompson Walder at (202) 586-8248. DOE and contractor personnel may obtain copies of these documents through the Internet/EH-41 Homepage (http://www.eh.doe.gov/oepa), Office of Science and Technical Information (OSTI) at (615) 576-8401, and Center for Environmental Management Information (CEMI) at 1-800736-3282.

\section{References}

Disposal Requirements for PCB Waste EH-231-056/1294, December 1994

The PCB Mark EH-231-057/1294, December 1994

PCB Recordkeeping and Reporting

EH-231-058/1294, December 1994

PCB Spill Response and Notification Requirements EH-231-059/1294, December 1994

PCB Storage Requirements EH-231-060/1294, December 1994

Questions of policy or questions requiring policy decisions will not be addressed in EH-413

Technical Assistance Projects unless that policy has already been established through appropriate documentation. Please refer any questions concerning the material covered herein to Carolyn Thompson Walder, EH-413, (202) 586-8248.

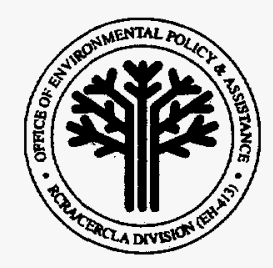

